\title{
Correction to: Updates in Chemoprevention Research for Hereditary Gastrointestinal and Polyposis Syndromes
}

Michael J Hall, MD, MS $\odot$

\section{Address}

Department of Clinical Genetics, Fox Chase Cancer Center, Philadelphia, PA, USA

Email: michael.hall@fccc.edu

Published online: 8 February 2021

(C) Springer Science+Business Media, LLC, part of Springer Nature 2021

The online version of the original article can be found at https://doi.org/10.1007/s11938-020-00306-x

\section{Correction to: Curr Treat Options Gastro https://doi.org/10.1007/s11938-020-00306-x}

The original article unfortunately contained a mistake. Data in Table 1 were incorrect. The original article has been corrected. 